\title{
Information Effect on Voter Turnout: How Campaign Spending Mobilises
}

\section{Voters}

Siim Trumm (University of Nottingham)

Laura Sudulich (University of Kent)

Joshua Townsley (University of Kent)

\begin{abstract}
We explore the impact of campaign effort on constituency-level turnout variation in Britain, under the premise that higher levels of campaign visibility stimulate electoral participation. We focus on the relationship between the competitiveness of the race and campaign effort as a provider of electoral information on the one hand, and voter turnout on the other hand. In doing so, we address the role of campaign effort and competitiveness in shaping turnout both independently as well as jointly. Further to this, we seek to add nuance to our understanding of how electoral campaigns mobilise voters by evaluating the comparative ability of different parties - based on whether or not they are 'viable' contenders in a particular constituency - to stimulate turnout. We find evidence that campaign effort mobilises voters and has a significant positive effect on voter turnout; this effect is independent from, and unconditioned by, the competitiveness of the race. However, we do find that this effect is mostly driven by the campaign effort of the 'viable' contenders in the constituency.
\end{abstract}

\section{Keywords}

Campaigns, electoral participation, competitiveness, campaign information, Great Britain 


\section{Introduction}

This paper is part of a special issue of Acta Politica entitled 'Information and Electoral Competition' edited by Sylvia Kritzinger, Susa Banducci, and Heiki Giebler. For much of the early post-war period in Britain, local electoral campaigns were often dismissed as being largely ineffective in terms of shaping electoral outcomes. Over the last three decades, however, extensive research has challenged and successfully shifted this consensus. As a result, there is now very little room for doubt left: local campaigns matter. Efforts put in place by candidates and parties in the run up to polling day clearly have an impact upon voters' choices. In addition, campaign effort also has a discernible positive effect on turnout (Geys 2006). The more intense, visible, and informative an electoral campaign is, the higher the likelihood of citizens casting a vote. While a myriad of other factors also contribute to explaining turnout and electoral results, the positive effects of local campaign effort on both of these phenomena are now widely accepted.

Campaign effort is the combination of activities aimed at maximising electoral gains. It serves the purpose of mobilising the electorate: from the core supporter to the undecided voter. It does so by enhancing the wider salience of the election as well as promoting the specific partisan message. In fact, campaign efforts put in place by political parties and candidates, together with intensive media coverage, are the two key sources of information available to voters in the run up to the election. Here, we focus on the former; specifically, we explore the impact of campaign effort on constituency-level turnout variation under the premise that more visible campaigns encourage electoral participation. Experimental studies have shown that citizens are more likely to vote when they are stimulated by exposure to campaign information (Green and Gerber 2008). In a similar vein, observational studies have shown that campaign mobilisation effort is a very powerful predictor of turnout not just in the US (Hillygus 2005), but across various electoral institutions (Karp and Banducci 2007; Karp et al. 2008).

We explore the extent to which local-level campaign effort actually affects turnout in the context of the 2010 British general election. Our analysis focuses on campaigning during the short campaign; i.e., from the dissolution of Parliament to polling day. We then turn to uncover whether the effects of campaign effort are moderated by the 
competitiveness of the race. While this is not an uncharted territory, little attention has to date been paid to the potential interaction between the competitiveness of a constituency race and campaign effort put in place by parties in the constituency. We add nuance and provide a more complete account of these effects by including the socalled minor parties, which are often neglected, to our analysis. While they often struggle to secure large numbers of MPs under Britain's first-past-the-post system, they represent an undeniably substantial electoral presence in British politics. Parties like the UK Independence Party and the Green Party are not just fielding increasing number of candidates at general elections, but are also enjoying growing vote shares. Moreover, regional parties like the Scottish National Party and Plaid Cymru are expanding their presence beyond the devolved institutions. Ultimately, there are more and more constituencies at Westminster elections where electorally relevant information is coming from parties other than Labour, the Conservatives, and the Liberal Democrats. As such, their effects should be taken into consideration. Our aim, therefore, is to take into account that the 'traditional' main parties are no longer the only salient providers of electoral information for voters in today's British political landscape.

We find strong evidence that both the aggregate constituency-level campaign effort put in place by all local candidates and the marginality of the seat affect turnout - i.e., the proportion of people choosing to cast their ballot is notably higher in marginal constituencies as well as in constituencies where parties spend more on their electoral campaigns. When disentangling this effect, we find, however, that the campaign effort put in place by the 'viable' contenders in the constituency has a far greater impact upon turnout than the effort of 'other' parties. Further to this, and against our theoretical expectations, we find no evidence that the competitiveness of the race conditions the positive effect of campaign effort, neither for the viable contenders in the constituency nor for the others. In other words, the local level effort to get out the vote by parties and candidates is equally important in marginal and safe seats.

The article is organised as follows. We first discuss the developments regarding voter turnout in Britain and survey the existing literature on campaign effort and electoral participation. This is done to draw our theoretical expectations and methodological approach. Then, we outline the rationale for our approach to assessing the effect of 
aggregate and disaggregate campaign effort on turnout. After this, we describe our data and measures. In the final section, we present and examine the findings, to then conclude with a discussion of their implications.

\section{Constituency-Level Electoral Dynamics}

We begin with a discussion of the dependent variable in the study; i.e., constituencylevel turnout. ${ }^{1}$ UK-wide turnout at the election to the House of Commons was $65 \%$ in 2010, but just like campaign effort, it varied greatly across different constituencies. The electoral system used for general elections in Britain accentuates the role of the local level in relation to both the competitiveness of the race as well as campaign intensity. One may reasonably assume that the campaign dynamics were different in a constituency like Aberavon - where the difference in the vote share between the winner and the runner up in 2005 was $46 \%$ - from those in places such as Ceredigion where the difference was $0.6 \%$ and the winner decided by only a handful of votes. In the former, voters may feel that turning out to vote is a rather pointless exercise, while in the latter each extra vote is more likely to be regarded as potentially decisive.

Over recent decades, the view that the national arena is the only meaningful level of competition (Kavanagh 1970) has been replaced. The conventional wisdom held that local-level campaigns in Britain, possibly more than in other contexts, were largely unimportant in shaping electoral outcomes. The potential impact of local campaigns was first raised in the 1970s by Denver and Hands (1974). They explored the role of local campaigns in mobilising the electorate and suggested that campaign spending (which they used as a proxy for campaign effort) might actually have a bigger impact on getting people out to vote than constituency marginality. Nowadays, the field of electoral politics in Britain has focused rather more on the sub-national level, following a considerable amount of research being produced on the effects of local campaigns on both voting behaviour (Fieldhouse and Cutts 2009; Fisher et al. 2011; Johnston et al. 2011; Johnston and Pattie 2006, 2008; Pattie et al. 1995) and turnout patterns (Fisher and Denver 2009; Denver et al. 2004). From studies of campaign effects on vote choice we know that, at general elections, British political parties have

\footnotetext{
${ }^{1}$ This is often referred to as the local level in the spending literature, while the literature on turnout generally labels it as the aggregate level to distinguish it from studies that address the determinants of individual-level turnout.
} 
proved their capacity to strategically target campaign efforts and, by and large, to make gains (or contain losses) where needed.

The case of the 2010 general election is of particular interest as the televised leaders debates are considered essential in explaining how it unfolded (Pattie and Johnston 2011; Stevens et al. 2011). If the information provided at the national level by the mass media saturates the demand for it, then electoral information produced by local campaign effort should in fact not be a significant predictor of turnout any longer. As such, digging deeper into the determinants of constituency-level turnout contributes to the debate on whether there is a shift towards 'TV elections' (Wring and Ward 2010) or whether the local level still continues to play a crucial role in mobilising electoral participation. A first piece of evidence supporting the latter scenario comes from a recent study by Fisher et al. (2016). They found that despite moves towards microtargeting voters, campaigning by the three largest parties in Britain increases turnout. However, this approach excludes the potential role of the so-called 'minor' parties as meaningful providers of electoral information, and also leaves aside the increasingly diverse combinations of parties that are serious contenders in many constituencies up and down Britain. Our contribution breaks from the 'traditional' three party frame and accounts for the role played by relative newcomers on the British electoral scene.

\section{Campaign Effort, Competitiveness and Electoral Participation}

When parties and their candidates actively engage with the electorate on the ground by intensifying the amount of activities aimed at winning votes in the run-up to the election, they simultaneously increase the amount of information on the election in general. While pursuing of course a partisan agenda, their campaign effort increases the salience of the election by intensifying the public debate surrounding it, as well as voters' exposure to it. Studies of negative campaigning show that the more intense campaign effort that is put in by parties and candidates (regardless of its content), the higher the likelihood of citizens casting a vote. ${ }^{2}$ Moreover, the general increase in late deciders (Hayes and McAllister 1996) suggests that 'late' campaign dynamics are likely to play an important role in determining variation in turnout. Therefore, we

\footnotetext{
${ }^{2}$ See, for example, Lau et al. (2007) for a comprehensive review of this literature.
} 
limit our analysis to the so-called short campaign, covering the campaign effort that took place in the immediate run up to the polling day.

In addition to the effects associated with campaign effort, the likelihood of casting a ballot should be particularly high when the election is expected to be a close race as the perceived utility of voting is greater in a marginal constituency than a safe one. Therefore, it is unsurprising that previous studies have found two constituency-level characteristics to be highly influential in determining how many people vote: marginality, as a measure of how competitive a particular constituency is, and campaign effort (Geys 2006). With regard to constituency marginality, it is widely accepted that when an election is a close contest, the probability that one vote might determine the outcome goes up. This, in turn, increases the perceived utility of voting and acts as an additional motivation to go to the polls. Matsusaka and Palda (1993) refer to it as the Downsian closeness hypothesis. Voters acknowledge that the benefits of casting their ballot are not just limited to merely fulfilling their sense of civic duty, which voting in very safe seats is arguably restricted to, but that they might have a chance of determining the result as well.

With regard to campaign effort, the more candidates invest in their campaigns in a given constituency, the greater their collective capacity to engage with the electorate and expose potential voters to electorally relevant information. As voters are exposed to more electioneering - defined by Bowler and Farrell (2011: 683) as the kinds of activities that get people out to vote - in their daily lives, the amount of information they have on candidates and their policy-positions is naturally increased as a result. Consequently, voters in constituencies with more intense campaign activity have to bear lower costs of information acquisition (Dawson and Zinser 1976; Chapman and Palda 1983), in turn, increasing their probability of casting a vote. We build on these two elements by exploring both their separate and joint effects.

\section{Combined and Separate Effort}

While studies addressing the effects of campaigning and competitiveness on electoral participation are not in short supply, our approach significantly departs from previous research in response to long-term changes in the British political landscape. Despite the high level of disproportionality that is typical of a first-past-the-post electoral 
system, 'minor' parties do contest elections and lately they have been doing so with significant success. The UK Independence Party gained nearly 1 million votes in 2010 and fielded 572 candidates, while the British National Party gained over half a million of votes, both notable increases from the previous general election in 2005. These two parties are of course not the only ones either. The Green Party stood 310 candidates in 2010 and secured its first ever seat in the House of Commons when Caroline Lucas was elected as MP for Brighton Pavilion. While the major traditional contenders are still receiving greater media attention, smaller parties are becoming increasingly effective players in the local context.

A second major change in recent years is the rise of regional parties - the Scottish National Party and Plaid Cymru in particular. These parties have been growing in size and popularity not only in the context of the devolved and local elections, but also with substantial success at the recent general elections. For instance, SNP won 6 seats in 2010, including Moray, with a 14\% majority, and came second in 27 other seats. At the same time, Plaid Cymru won 3 Westminster seats in Wales, including Dwyfor Meirionnydd with a $22 \%$ majority. Therefore, the campaign efforts put in place by the so-called minor and regional parties are no longer negligible when studying activities that stimulate turnout. Yet, the scholarly tradition on the matter tends to focus merely on the activities of the three (traditionally) largest parties: Labour, Conservatives, and Liberal Democrats (Denver and Hands, 1997; Denver et al. 2004; Fieldhouse and Cutts 2009; Fisher 1999; Fisher et al. 2014). Given the changing landscape of who is and who is not a relevant actor in the context of British elections, limiting the analysis to the campaign efforts put in place by Labour, Conservatives, and Liberal Democrats may omit potentially crucial information needed to explain the effects of campaign effort on turnout.

As such, we depart from the traditional approach by exploring the effects of campaign effort put in place by all parties that are contesting a constituency. In doing so, we explore whether the aggregate effort of all parties in play is responsible for variation in constituency-level turnout. Next to that, we still account for the fact that certain parties might be more influential than others in mobilising the electorate as shown, for example, by Fisher et al. (2016). However, we avoid imposing a fixed constraint that treats certain parties - generally Labour, Conservatives, and Liberal Democrats - as 
the most relevant ones irrespective of the constituency in question. Instead, we allow for the possibility that in different seats, different sets of parties are the most relevant players. For example, the three viable contenders in the marginal seat of Watford in 2010 were the usual suspects: Labour, Conservatives, and Liberal Democrats. Between them, they secured 94 per cent of all votes cast. Meanwhile, in the Na hEileanan an Iar constituency in Scotland the viable contenders were the SNP, the Scottish Labour Party, and an Independent candidate Murdo Murray, receiving a combined vote share of $88 \%$. The latter is by no means a stand-alone example. In fact, it illustrates a broader trend whereby the power of the traditional 'big three' is being eroded in more and more Westminster constituencies. Therefore, our approach accounts for different combinations of parties in a constituency by setting apart the campaign efforts of (a) 'viable contenders' - those that have a realistic chance of winning the seat regardless of what party they represent - from (b) 'other contenders' who are not realistically in with a chance of winning the seat.

Empirically, this choice results in two parallel sets of models: the first set accounts for the combined campaign effort of all parties contesting the election in a constituency. The second set then disentangles campaign effort on the basis of previous party performance in the constituency by focusing on the campaign effect associated with the parties of a particular standing in the given constituency. On the one hand, it is sensible to expect that the higher the aggregate campaign effort of all parties contesting the election in a constituency, the higher the turnout. On the other hand, past studies have proven the differential capacity across parties, leading us to expect that the positive effect of campaign effort on turnout is stronger for viable contenders than other contenders. While our specification of 'main' parties differs from previous studies by looking at the specific dynamics of party competition in each seat, there is no reason to expect invariance.

In addition to testing the above, we also explore the interplay between the campaign effort put in place in a constituency (aggregate as well as disaggregate) and the degree of electoral competitiveness within the constituency. Although previous studies have shown that both are useful predictors of turnout on their own, the extent to which the competitiveness of the race might moderate the positive effect of campaign effort remains unexplored. As electorally relevant information serves the purpose of 
enhancing the visibility of the election, its positive effect on voters' likelihood of casting a ballot should be stronger in a constituency where the likelihood of this vote making a difference is higher. As such, we expect the effects of campaign effort to be conditioned by the marginality status of the race and we empirically test for the potential interaction effect between marginality and campaign effort.

\section{Data and Measures}

Parliamentary candidates in Britain are obliged by law to disclose their campaign expenditure. This allows us to use official electoral returns data provided by the UK Electoral Commission (2016) to account for constituency-level campaign effort in the run up to the 2010 general election. Relying on official campaign spending data has several unique advantages: it covers all candidates and parties - i.e., it is not subject to missing observations in a manner that self-reported spending measures in election surveys are - and, crucially, is more reliable than the survey-based and self-reported measures of campaign spending. Our analysis encompasses the short campaign when parties and candidates intensify their campaign efforts in order to secure the votes of the undecided voters and those who might otherwise be inclined not to vote at all. We then integrate this information with constituency-level turnout data and various socioeconomic indicators from the most recent 2011 Census.

\section{Dependent Variable and Core Explanatory Variables}

The dependent variable in our study - turnout - is operationalised as the percentage of registered voters in the given constituency who cast a valid vote at the 2010 general election.

The first core explanatory variable - marginality - is measured as the difference between the winner's and runner up's vote share at the previous election in percentage points. ${ }^{3}$ It describes the expected competitiveness of the race in a given constituency. ${ }^{4}$ As such, this difference effectively characterises the lead that the winner had in 2005

\footnotetext{
${ }^{3}$ As a result of the Fifth Periodic Review of Westminster, the actual 2005 results could not be used to gauge the marginality of some constituencies. We rely on estimates of the 2005 results as if the election had been conducted under the new boundaries for those constituencies (Rallings and Thrasher 2007).

${ }^{4}$ For further discussion on the appropriateness of relying on the expectations about the closeness of the race to count for the expected vote see, for example, Bonneau (2007).
} 
over her/his runner up. Being an inverse measure of competitiveness, higher values indicate that the seat is safer and lower values indicate that the seat is more marginal.

We also operationalise marginality in terms of marginality status. This is measured as a categorical variable, distinguishing between safe seats, two-way marginal seats, and three-way marginal seats. Constituency is coded safe if the difference in vote share between the winner and runner-up was more than $10 \%$ in 2005, two-way marginal if this difference was below $10 \%$ (but the third-placed party was more than $10 \%$ off the winner), and three-way marginal if the vote shares of the three most popular parties in the constituency were within $10 \%$ in 2005 .

The second core explanatory variable is campaign spending in a given constituency during the short campaign. In line with a large tradition of studies in Britain (Fisher 2015; Johnston et al. 1989; Johnston and Pattie 1994; Pattie et al. 1995; Whiteley and Seyd 1994) and elsewhere (Benoit and Marsh 2003, 2008, 2010; Maddens et al. 2006; Sudulich and Wall 2011; Wauters et al. 2010) we use a proxy measure for campaign effort in the form of electoral expenditure. In a comprehensive meta-analysis, Geys (2006) shows that electoral spending data are consistently one of the most significant predictors of turnout, and we have no reason to expect otherwise. In addition to the fact that the use of campaign spending as an indicator of campaign effort is common practice, Fisher et al. (2016) have recently provided further evidence demonstrating that official electoral returns produce robust estimates to those based on survey measures of campaign activity. Gauging campaign effort is renowned for being difficult (Cutts and Fieldhouse 2009), with every measure presenting advantages and disadvantages. While spending data are limited in their capacity to capture nuances, they have higher reliability than survey-based measures and do not suffer from nonresponse given the abovementioned legal requirement to report spending returns.

We aggregate candidates' electoral expenditures at constituency level - representing the overall amount spent in each constituency - and divide it by the legal spending limit in the given constituency. Candidate spending in Britain is limited by law and varies by both the electorate size and the geography of the constituency. Therefore, a relative measure of campaign spending is more appropriate for comparing campaign intensity across constituencies. In addition to total campaign spending, and to assess 
the mobilisation effects associated with the campaign efforts put in place by different parties in each constituency, we also build separate variables for the relative spending of the viable contenders in each constituency, i.e., those with a realistic chance of winning the seat (Campaign Spending - Viable Contenders), and the other parties in each constituency (Campaign Spending - Other Contenders).

We distinguished between viable and other contenders in each constituency according to its marginality status as follows. First, we separated constituencies that are safe, two-way marginal (i.e., have two close contenders), and three-way marginal (i.e., have three close contenders). We counted as 'viable contenders' those parties that are in with a realistic chance of winning in each type of seat based on their performance at the previous election. For instance, in a safe seat, the only 'viable contender' is the party that finished first at the previous election. In the abovementioned seat of Aberavon for example, this would be Labour. Alternatively, in two-way and threeway marginal constituencies, the 'viable contenders' are the top two and three parties, respectively. For example, the Ochil and South Perthshire constituency was a threeway marginal following the 2005 general election with Labour on $31.4 \%$, SNP on $29.9 \%$, and the Conservatives on $21.5 \%$. In this instance, the viable contenders were Labour, SNP, and the Conservatives, each representing a significant campaigning presence in this constituency. Whereas the conventional approach would only capture the campaign effort of Labour and the Conservatives in this seat, our approach captures the campaigning effort of the SNP. This allows us to take into account the specific dynamics of each seat's competitiveness when capturing the effect of the 'viable' contenders' campaign efforts compared to those of the other parties.

Finally, we run a robustness check of Models 1 and 2 - reported in the Appendix - by controlling only for previous turnout under the assumption that it would account for marginality and the other controls. Results are in line with what is presented here.

\section{Other Explanatory Variables and Controls}

Constituency-level turnout is of course not just a function of campaign spending and marginality. Therefore, we control for the social dimension of electoral participation as well as the economic composition of the electorate in the constituency by including several constituency-specific demographics in the analysis. We account for the former 
by controlling for single occupancy households on the premise that people who do not share their residency are likely to receive fewer social cues associated with voting. Household dynamics have been shown to significantly influence voter participation (Cutts and Fieldhouse 2009). For example, individuals residing in single occupancy households are less likely to be stimulated to vote through talking to others about the upcoming election at home. It is operationalised as the percentage of people in the constituency who live in a single-person household and we expect it to have a negative effect on turnout. We account for the latter by controlling for economic factors in the shape of social class. It is a widely used demographic classification, indicating socio-economic position based mainly on one's occupation. The measure is operationalised as the percentage of working-age people in the constituency who are, according to Census 2011, in the top two analytical classes of the National Statistics Socio-Economic classification. We expect to see a positive effect on turnout as more affluent voters are likely to have more time and resources that they can invest in being politically active (Schlozman et al. 2012).

We also include two control variables in the analysis. We explore the effect that the size of the electorate has on turnout, operationalised as the number of eligible voters in the district in thousands. As the size of the electorate increases, the probability that a single vote might influence the election outcome decreases. Therefore, following Downs' (1957) 'calculus-of-voting' model in which voters are instrumentally rational, we expect larger constituencies in terms of the electorate size to experience weaker turnout. Finally, we control for constituency type by setting apart those that are rural (county) from those that are urban (borough/burgh).

\section{Empirical Strategy}

Given that our dependent variable - turnout - is normally distributed, we implement OLS models with robust standard errors. Our analysis includes all 2010 Westminster constituencies in Britain ${ }^{5}$ for which the Electoral Commission received full spending returns, with the exception of the Speaker's constituency as it is traditionally not contested by major parties. The final sample includes 615 constituencies.

\footnotetext{
5 The 17 constituencies in Northern Ireland are, therefore, excluded.
} 


\section{Findings and Discussion}

We begin by looking at the effects of aggregate campaign spending (i.e., cumulative constituency-level campaign spending by all candidates who stood for election in the given constituency) on turnout in Model 1 (Table 1 below). As expected, and in line with what has been found by previous studies, constituency marginality and campaign effort are both good predictors of turnout. The positive and significant coefficient for campaign spending shows that where candidates' cumulative campaign expenditure is higher, more voters choose to cast their ballot. Turnout is expected to rise by almost 0.6 per cent when the combined spending of all candidates in the constituency - as a proportion of the legal spending limit - increases by 1 per cent. ${ }^{6}$ The negative and significant coefficient for marginality shows that turnout is higher when the seat is more competitive; i.e., the difference between the winner's and runner up's vote share was smaller in the previous election. We also find that turnout is lower where more people live in one-person households and the electorate is larger, while it is higher in constituencies that have a higher proportion of working-age population in the top social classes. These empirical findings follow our theoretical expectations and are also in line with the indications provided by existing literature on turnout.

Table 1. Explaining Variation in Voter Turnout with Campaign Spending

\begin{tabular}{|c|c|c|}
\hline & \multicolumn{2}{|c|}{$\begin{array}{c}\text { Turnout } \\
2010 \text { General Election }\end{array}$} \\
\hline & $(1)$ & $(2)$ \\
\hline Campaign Spending - Total & $.59 *(.23)$ & \\
\hline Campaign Spending - Viable Contenders & & $1.22 * *(.41)$ \\
\hline Campaign Spending - Other Contenders & & $.48 *(.24)$ \\
\hline Marginality & $-.10 * * *(.01)$ & $-.08 * * *(.02)$ \\
\hline Single Occupancy Household & $-.40 * * *(.05)$ & $-.40 * * *(.05)$ \\
\hline Social Class & $.42 * * *(.02)$ & $.42 * * *(.02)$ \\
\hline Electorate & $-.09 * * *(.02)$ & $-.09 * * *(.02)$ \\
\hline \multicolumn{3}{|l|}{ Constituency Type ${ }^{\wedge}$} \\
\hline County & $2.70 * * *(.28)$ & $2.70 * * *(.28)$ \\
\hline Constant & $69.95 * * *(2.38)$ & $69.08 * * *(2.44)$ \\
\hline Number of Constituencies & 615 & 612 \\
\hline $\mathrm{R}^{2}$ & .71 & .71 \\
\hline
\end{tabular}

\footnotetext{
${ }^{6}$ The legal spending limit was between $£ 10,000$ and $£ 13,000$ for the vast majority of the constituencies used in the analysis.
} 
In Model 2 (Table 1) we explore the extent to which campaign mobilisation effects vary across parties. We do so by distinguishing between the campaign efforts put in place by viable contenders in the constituency (based on the seat's marginality status) and other contenders. The disaggregated analysis indicates that there are several crucial differences in the extent to which more intense campaign efforts put in place by different parties stimulate electoral participation. The effects we observed in Model 1 are clearly driven first and foremost by the campaign efforts of viable contenders. The comparison of coefficients for viable and other contenders indicates that campaign spending by the former has over two times the effect on turnout than that of the latter. In order to better illustrate this, Figure 1 shows the predicted turnout at all levels of cumulative campaign spending by viable contenders and other contenders. The clear difference in the steepness of the lines indicates that the effect sizes associated with campaign mobilisation efforts put in place by viable and other contenders do in fact vary notably. For example, predicted turnout rises by $3.6 \%$ when viable contenders' cumulative spending increases from no spending to three times the legal limit in the constituency, whereas only by $1.4 \%$ when a similar shift in the cumulative spending of other contenders takes place.

Figure 1. Effects of Viable Contenders' and Other Contenders' Spending on Turnout
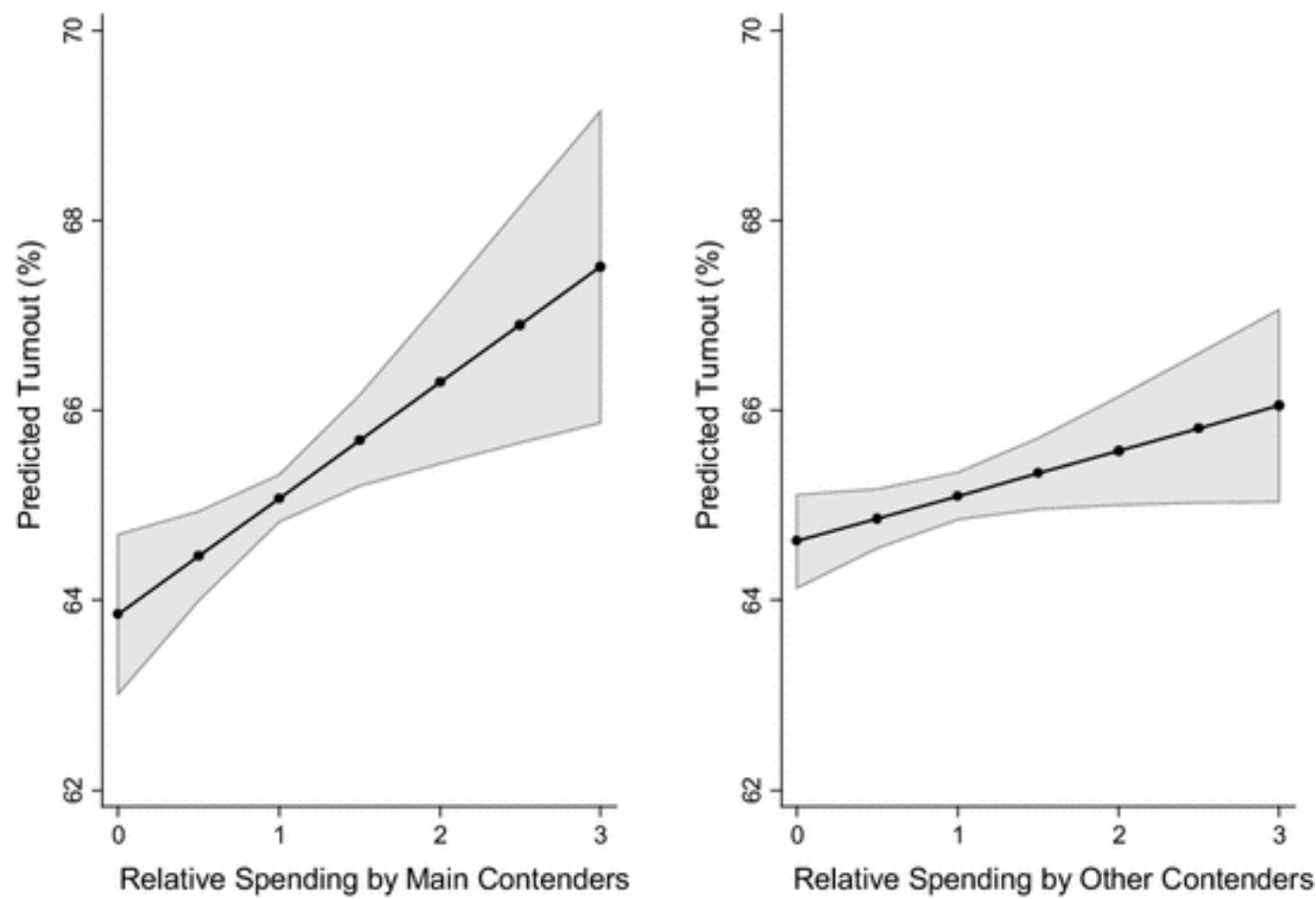
Figure 1 does confirm our expectation that parties differ in their capacity to mobilise voters in line with their prominence in the constituency. The higher the local standing of the party is, the stronger its ability to mobilise voters. This builds on the findings by Fisher et al. (2016), but indicates also that a party's ability to bring voters to the polls is not necessarily determined by its national size and/or presence. Rather, its local status has a meaningful impact on its ability to mobilise voters.

Having explored the effects of campaign effort and marginality on turnout separately, we now move to assessing whether their effects are conditioned by one other. Table 2 below presents the result of the multiplicative models.

Table 2. Explaining Variation in Turnout with Campaign Spending by Marginality

\begin{tabular}{|c|c|c|}
\hline & \multicolumn{2}{|c|}{$\begin{array}{c}\text { Turnout } \\
2010 \text { General Election }\end{array}$} \\
\hline & $(3)$ & $(4)$ \\
\hline Campaign Spending - Viable Contenders & $2.95 * * *(.76)$ & $3.35 * * *(.59)$ \\
\hline \multicolumn{3}{|l|}{ Marginality Status^ } \\
\hline Two-Way Marginal & $-1.42(1.68)$ & $-0.70(.79)$ \\
\hline Three-Way Marginal & $-10.21(5.74)$ & $-3.12(2.37)$ \\
\hline \multicolumn{3}{|l|}{ Marginality Status ${ }^{\wedge} *$ Campaign Spending - Viable Contenders } \\
\hline Two-Way Marginal & $0.75(1.26)$ & \\
\hline Three-Way Marginal & $3.59(2.55)$ & \\
\hline Campaign Spending - Other Contenders & $0.75 * *(0.25)$ & $0.68 *(0.27)$ \\
\hline \multicolumn{3}{|l|}{ Marginality Status $\wedge *$ Campaign Spending - Other Contenders } \\
\hline Two-Way Marginal & & $0.19(.61)$ \\
\hline Three-Way Marginal & & $5.09(8.91)$ \\
\hline Single Occupancy Household & $-0.41 * * *(.05)$ & $-0.41 * * *(.05)$ \\
\hline Social Class & $0.43 * * *(.02)$ & $0.43 * * *(.02)$ \\
\hline Electorate & $-0.08 * * *(.02)$ & $-0.08 * * *(.02)$ \\
\hline \multicolumn{3}{|l|}{ Constituency Type ${ }^{\wedge \wedge}$} \\
\hline County & $2.94 * * *(.28)$ & $2.92 * * *(.28)$ \\
\hline Constant & $64.89 * * *(2.45)$ & $64.75 * * *(2.42)$ \\
\hline Number of Constituencies & 612 & 612 \\
\hline $\mathrm{R}^{2}$ & .70 & .70 \\
\hline
\end{tabular}

Model 3 includes an interaction between the campaign spending of viable contenders in a constituency and marginality, while Model 4 presents an interaction between the spending of other contenders and marginality. We find that the effects of campaign effort are not conditioned by the competitiveness of the race. This is consistent across both models. Although the direction of the interaction is generally in line with our theoretical expectations, there is no substantial evidence of moderating effects. 
The insignificant interaction terms suggest that higher levels of electoral information drive voters to the polls in constituencies where the race is open (between two or three viable competitors) as much as they do in safe constituencies (with only one viable candidate). While this goes against our initial expectations, it has an important realworld meaning: campaign efforts aimed at enhancing the visibility of the election contribute to electoral participation irrespective of electoral competitiveness.

\section{Conclusions}

In this study, we explored the impact of campaign intensity on turnout by looking at the aggregate constituency-level campaign effort to get out the vote by all parties. We did so under the premise that restricting the analysis to the traditional main parties in Britain - Labour, Conservatives, and Liberal Democrats - limits our understanding of how electioneering stimulates turnout. This is the first attempt to account for a rapidly changing political landscape in Britain, where several other parties are experiencing significant growth in membership and electoral support. These parties, in turn, are choosing to deploy more and more campaign resources in their bids to win seats in the House of Commons. We find that increased campaign effort, through the provision of electoral information, leads to higher levels of voting, ceteris paribus. The availability of information reduces the costs associated with voting which, in turn, increases the likelihood of citizens casting a ballot.

Next to quantifying the impact of aggregate campaign effort, we also disaggregate its effects by party - setting them apart on the basis of whether or not they were 'viable contenders' in the constituency. Our approach allows for different combinations of parties to be treated as the 'viable' ones in a particular constituency, accounting for the increasingly dynamic dynamics of British politics at the local level. Our findings from the disaggregate analysis show that the effects of campaign effort on turnout are nearly three times stronger when carried out by parties that are viable contenders in the constituency than those who are not. This applies regardless of which exact parties count as 'viable' contenders in the constituency.

We then expand on how competitiveness of the race influences electoral participation. While marginality has a discernible impact on turnout in line with our expectations, it 
does not condition the effectiveness of campaign effort (aggregate or disaggregate). In other words, no matter how competitive the race is expected to be in the constituency, making more electorally relevant information available to voters has a positive effect on turnout.

There are three key points arising from this study. First, given the changing dynamics of British politics, future research should look beyond the 'traditional' major players in the shape of the Labour Party, the Conservative Party, and the Liberal Democrats. It is important to account for the considerable, and increasingly successful, campaign efforts made by other parties contesting Westminster elections. For example, around $12 \%$ of all votes cast at the 2010 general election went to parties other than Labour, Conservatives, and Liberal Democrats. At the 2015 general election, this more than doubled to approximately 25\%. In Scotland, a former Labour heartland, the SNP won all but 3 seats in the House of Commons in 2015, while the UK Independence Party actually supplanted the Liberal Democrats as the third most popular party in Britain in terms of vote share by receiving 3.9 million votes to the Liberal Democrats' 2.4 million. Accounting for these changes in the British electoral landscape is, therefore, unavoidable.

Second, the lack of significant interaction effects between campaign effort on the one hand and marginality on the other hand suggests that providing information to voters is equally helpful in getting out the vote in safe and marginal constituencies. This has significant implications on how one should think about campaigning in these electoral contexts. Under the first-past-the-post system, the incentives to vote in safe seats are limited, particularly for those who do not support the incumbent party. This can, in turn, understandably be perceived by parties and candidates as a disincentive to spend resources in such constituencies. Our findings, however, indicate that even under such conditions the information provided by the challenger parties through their campaign efforts still act as a trigger for greater electoral participation.

Finally, our findings testify for the relevance of local electoral campaigns by showing that constituency-level dynamics have not been completely overshadowed by the TV debates. This brings into question the notion that the 2010 general election was the 'TV election' (Johnston and Pattie 2011), by showing that parties at local level 
continued to play a pivotal role in providing information to voters in the run up to polling day.

\section{Bibliography}

Benoit, K. and Marsh, M. 2003. For a Few Euros More: Campaign Spending Effects in the Irish Local Elections of 1999. Party Politics 9(5): 561-582.

Benoit, K. and Marsh, M. 2008. The Campaign Value of Incumbency: A New Solution to the Puzzle of Less Effective Incumbent Spending. American Journal of Political Science 52(4): 874-890.

Benoit, K. and Marsh, M. 2010. Incumbent and Challenger Campaign Spending Effects in Proportional Electoral Systems: The Irish Elections of 2002. Political Research Quarterly 63(1): 159-173.

Bonneau, C.W. 2007. The Effects of Campaign Spending in State Supreme Court Elections. Political Research Quarterly 60(3): 489-499.

Bowler, S. and Farrell, D.M. 2011. Electoral Institutions and Campaigning in Comparative Perspective: Electioneering in European Parliament Elections. European Journal of Political Research 50(5): 668-688.

Chapman, R. G. and Palda, K, S. 1983. Electoral Turnout in Rational Voting and Consumption Perspectives. Journal of Consumer Research 9: 337-346.

Cutts, D. and Fieldhouse, E. 2009. What Small Spatial Scales Are Relevant as Electoral Contexts for Individual Voters? The Importance of the Household on Turnout at the 2001 General Election. American Journal of Political Science 53(3): 726-739.

Dawson, P. and Zinser, J. 1976. Political Finance and Participation in Congressional Elections. Annals of the American Academy of Political and Social Science 425159-73.

Denver, D.T. and Hands, H.T.G. 1974. Marginality and Turnout in British General Elections. British Journal of Political Science 4(1): 17-35.

Denver, D.T. and Hands, H.T.G. 1977. Challengers, Incumbents, and the Impact of Constituency Campaigning in Britain. Electoral Studies 16(2): 175-193.

Denver, D., Hands, H.T.G. and MacAllister, I. 2004. The Electoral Impact of Constituency Campaigning in Britain, 1992-2001. Political Studies 52(2): 289-306. 
Downs, A. 1957. An Economic Theory of Democracy. New York: Harper and Row.

Electoral Commission. 2016. Previous UK General Elections. Available at: http://www.electoralcommission.org.uk/find-information-by-subject/electionsand-referendums/past-elections-and-referendums/uk-general-elections [Accessed on 23/03/2016].

Farrell, D.M. and Schmitt-Beck, R. 2004. Do Political Campaigns Matter? Campaign Effects in Elections and Referendums. London: Routledge.

Fieldhouse, E. and Cutts, D. 2009. The Effectiveness of Local Party Campaigns in 2005: Combining Evidence from Campaign Spending and Agent Survey Data. British Journal of Political Science 39(2): 367-388.

Fisher, J. 1999. Party Expenditure and Electoral Prospects: a National Level Analysis of Britain. Electoral Studies 18: 519-532.

Fisher, J. 2015. Party Finance: The Death of the National Campaign? Parliamentary Affairs 68(1): 133-153.

Fisher, J., Cutts, D. and Fieldhouse, E. 2011. The Electoral Effectiveness of Constituency Campaigning in the 2010 British General Election: The ‘Triumph' of Labour? Electoral Studies 30(4): 816-828.

Fisher, J. and Denver, D. 2009. Evaluating the Electoral Effects of Traditional and Modern Modes of Constituency Campaigning in Britain 1992-2005. Parliamentary Affairs 62(2): 196-210.

Fisher, J., Johnston, R., Cutts, D., Pattie, C. and Fieldhouse, E. 2014. You Get What You (Don't) Pay For: The Impact of Volunteer Labour and Candidate Spending at the 2010 British General Election. Parliamentary Affairs 67(4): 804-824.

Fisher, J., Fieldhouse, E., Johnston, R., Pattie, C. and Cutts, D. 2016. Is All Campaigning Equally Positive? The Impact of District Level Campaigning on Voter Turnout at the 2010 British General Election. Party Politics 22(2): 215226.

Geys, B. 2006. Explaining Voter Turnout: A Review of Aggregate-level Research. Electoral Studies 25(4): 637-663.

Green, D.P. and Gerber, A.S. 2008. Get Out the Vote: How to Increase Voter Turnout. Washington: Brookings Institution Press.

Hayes, B. C. and McAllister, I. 1996. Marketing Politics to Voters: Late Deciders in the 1992 British Election. European Journal of Marketing 30(10/11): 127-139. 
Hillygus, D.S. 2005. Campaign Effects and the Dynamics of Turnout Intention in Election 2000. Journal of Politics 67(1): 50-68.

Johnston, R.J., Pattie, C. and Johnston, L.C. 1989. The Impact of Constituency Spending on the Result of the 1987 British General Election. Electoral Studies 8(2): 143-155.

Johnston, R.J. and Pattie, C. 1994. The Impact of Party Spending on Party Constituency Campaigns at Recent British General Elections. Party Politics 1(2): 261-273.

Johnston, R.J. and Pattie, C. 2008. How Much Does a Vote Cost? Incumbency and the Impact of Campaign Spending at English General Elections. Journal of Elections, Public Opinion and Parties 18(2): 129-152.

Johnston, R.J., Rossiter, D. and Pattie, C. 2008. Far Too Elaborate About So Little: New Parliamentary Constituencies for England. Parliamentary Affairs 6(1): 430.

Johnston, R.J. and Pattie, C. 2011. Electoral Systems, Geography, and Political Behaviour: United Kingdom Examples. In B.Warf and J.Leib (eds.) Revitalizing Electoral Geography. Burlington: Ashgate Publishing Company, pp. 31-58.

Johnston, R.J., Pattie, C., Cutts, D., Fieldhouse, E. and Fisher, J. 2011. Local Campaign Spending at the 2010 General Election and Its Impact: Exploring What Wider Regulation Has Revealed. The Political Quarterly 82(2): 169192.

Johnston, R.J. and Pattie, C. 2006. Putting Voters in Their Place: Geography and Elections in Great Britain. Oxford: Oxford University Press.

Karp, J.A. and Banducci, S.A. 2007. Party Mobilization and Political Participation in New and Old Democracies. Party Politics 13(2): 217-234.

Karp, J.A., Banducci, S.A. and Bowler, S. 2008. Getting Out the Vote: Party Mobilization in a Comparative Perspective. British Journal of Political Science 38(1): 91-112.

Kavanagh, D. 1970. Constituency Electioneering in Britain. London: Longmans.

Lau, R.R., Sigelman, L. and Brown Rovner, I. 2007. The Effects of Negative Political Campaigns: A Meta-Analytic Reassessment. Journal of Politics 69(4): 11761209. 
Maddens, B., Wauters, B., Noppe, J. and Fiers, S. 2006. Effects of Campaign Spending in an Open List PR System: The 2003 Legislative Elections in Flanders/Belgium. West European Politics 29(1): 161-168.

Matsusaka, J.G. and Palda, F. 1993. The Downsian Voter Meets the Ecological Fallacy. Public Choice 77(4): 855-878.

Pattie, C., Johnston, R.J. and Fieldhouse, E. 1995. Winning the Local Vote: The Effectiveness of Constituency Campaign Spending in Great Britain, 19831992. American Political Science Review 89(4): 969-983.

Pattie, C. and Johnston, R. 2011. A Tale of Sound and Fury, Significant Something? The Impact of the Leaders' Debates in the 2010 UK General Election. Journal of Elections, Public Opinion and Parties 21(2): 147-177.

Rallings, C. and Thrasher, M. 2007. The Media Guide to the New Parliamentary Constituencies. Plymouth: LGC Elections Centre.

Schlozman, K.L., Verba, S. and Brady, H.E. 2012. The Unheavenly Chorus: Unequal Political Voice and the Broken Promise of American Democracy. Princeton: Princeton University Press.

Stevens, D., Karp, J.A. and Hodgson, R. 2011. Party Leaders as Movers and Shakers in British Campaigns? Results from the 2010 Election. Journal of Elections, Public Opinion and Parties 21(2): 125-145.

Sudulich, L. and Wall, M. 2011. How Do Candidates Spend Their Money? Objects of Campaign Spending and the Effectiveness of Diversification. Electoral Studies, 30(2): 91-111.

Wauters, B., Weekers, K. and Maddens, B. 2010. Explaining the Number of Preferential Votes for Women in an Open-List PR System: An Investigation of the 2003 Federal Elections in Flanders (Belgium). Acta Politica 45(4): 468490.

Whiteley, P. and Seyd, P. 1994. Local Party Campaigning and Voting Behaviour in Britain. Journal of Politics 56(1): 242-151.

Wring, D. and Ward, S. 2010. The Media and the 2010 Campaign: The Television Election? Parliamentary Affairs 63(4): 802-817.

\section{Appendix A. Robustness Check}


Table A1 displays findings from models where previous turnout in the constituency is used to control for the profile of the constituency instead of marginality and socioeconomic characteristics. It is operationalised as the percentage of voters who cast a valid vote at the 2005 general election in the constituency. The findings reported in Table A1 are in line with those presented in the main text. Campaign spending aggregate and disaggregate - consistently has positive effects on turnout, while the effect sizes associated with campaign spending by viable and other contenders are comparable and remain within a rough $2: 1$ ratio.

Table A1. Previous Turnout and Campaign spending as predictors of Turnout

\begin{tabular}{|c|c|c|}
\hline & \multicolumn{2}{|c|}{$\begin{array}{c}\text { Turnout } \\
2010 \text { General Election }\end{array}$} \\
\hline & $(\mathrm{A} 1.1)$ & (A1.2) \\
\hline Campaign Spending - Total & $0.91 * * *(.18)$ & \\
\hline Campaign Spending - Viable Contenders & & $1.13 * * *(.24)$ \\
\hline Campaign Spending - Other Contenders & & $0.70 * *(.23)$ \\
\hline Previous Turnout & $0.77 * * *(.03)$ & $0.76 * * *(.03)$ \\
\hline Constant & $16.65 * * *(1.68)$ & $16.89 * * *(1.74)$ \\
\hline Number of Constituencies & 615 & 615 \\
\hline $\mathrm{R}^{2}$ & .74 & .75 \\
\hline
\end{tabular}

Standard errors in parentheses; $* * * \mathrm{p}<0.001, * * \mathrm{p}<0.01, * \mathrm{p}<0.05$. 